\title{
Maternal Weight Gain and its Relationship with Birth Weight of Baby at Term
}

\author{
SHIFFIN RIJVII ${ }^{1}$, SHARMIN ABBASI ${ }^{2}$, FARHANA DEWAN ${ }^{3}$, SEHEREEN FARHAD SIDDIQUA ${ }^{4}$, \\ ANURADHAKARMAKAR ${ }^{5}$
}

\begin{abstract}
:
Background: Perinatal health is influenced by maternal weight gain. Increase in obesity in population and excess weight during pregnancy may be different complications including large for gestational age fetus. As a result cesarean delivery has increased in prevalence. Maternal weight gain during the $2^{\text {nd }}$ and $3^{\text {rd }}$ trimesters is an important determinant of fetal growth

Objective: To determine the relationship between maternal weight gain and birth weight of baby at term.

Methodology : A cross sectional study was carried among 50 pregnant women at term in the Department of Obstetrics and Gynaecology, Shaheed Suhrawardy Medical College and Hospital and Anwer Khan Modern Medical College Hospital during the period of January 2013 to July 2013. Data were collected in pre-designed data collection sheet.

Results: This study found maximum (36\%) were age group 21-25 years followed by $28 \%$ were $\leq 20$ years, $24 \%$ were between $26-30$ years, $8 \%$ were between $31-35$ years and only $4 \%$ were of $36-40$ years. The average age was 25 years. Among these 50 pregnant women, 2 cases (4\%) had BMI < 18.5, 15 cases (30\%) had a BMI 18.5-24.9, 19 cases (38\%) had a BMI 25-29.9 and 14 cases (28\%) had a BMI $\geq 30$. The mean birth weight was $2.77 \pm 0.33$. $\mathrm{kg}$. Mean weight gain was $10.72 \pm 3.72 \mathrm{Kg}$.

Conclusion: This study showed that reasonable maternal weight gain significantly increased birth weight of the baby at term.
\end{abstract}

Key word: Maternal weight gain in pregnancy, Birth weight of baby

Introduction:

Birth weight is an important predictor for survival and health. ${ }^{1}$ Infants with a low birth weight (less than 2,500 $\mathrm{g}$ ) or overweight when (more than $4000 \mathrm{~g}$ ) have increased perinatal morbidity and mortality as well as an increased risk of adulthood hypertension and type 2 diabetes. ${ }^{2}$ For many years the focus has been on increasing birth weight, which is positively correlated with maternal weight gain during pregnancy. However, although a high maternal weight gain tend to decrease the incidence of low birth weight, an excessive weight gain may entail fetal as well as maternal complications, such as pregnancy and delivery complications and obesity later in life. ${ }^{3}$

Prepregnancy body mass index (BMI) is an important predictor of birth weight. It is therefore important to combine maternal weight gain and prepregnancy BMI in analyses of the association between weight gain and infant birth weight. American Institute of Medicine (IOM) introduced weight gain recommendations for pregnant women with different recommendations for

1. Registrar Dept. of Obstetrics and Gynecology, Anwer Khan Modern Medical College Hospital

2. Assistant Professor, Dept. of Obstetrics and Gynecology, Anwer Khan Modern Medical College hospital

3. Head, Dept. of Obstetrics and Gynecology, Shaheed Suhrawardy Medical College and Hospital

4. Head Dept. of Obstetrics and Gynecology, Anwer Khan Modern Medical College Hospital

5. Registrar, Dept. of Obstetrics and Gynecology Delta Medical College Hospital

Address of Correspondence: Dr. Shiffin Rijvi, Registrar Dept of obstetrics and gynecology Anwer Khan Modern Medical College Hospital 
underweight (BMI less than $19.8 \mathrm{~kg} / \mathrm{m} 2$ ), normal weight $(19.8-26.0 \mathrm{~kg} / \mathrm{m} 2)$, overweight (26.1-29.0 $\mathrm{kg} / \mathrm{m} 2$ ), and obese women (BMI more than $29.0 \mathrm{~kg} /$ $\mathrm{m} 2)^{2}$

Weight gain during pregnancy has been associated with high birth weight and measures of adiposity early in life. Because high birth weight predicts BMI later in life, these findings suggest that excessive weight gain during pregnancy could raise the long-term risk of obesity-related disease in offspring. High birth weight might also increase risk of other diseases later in life, including asthma, atopy, and cancer. ${ }^{3}$

Low weight gain in pregnancy is associated with increased risk of preterm delivery, particularly if women are underweight or of average weight before pregnancy. But still there is increasing evidence that higher weight gains during pregnancy do not improve infant outcomes and instead may elevate the mothers' long-term risk of chronic disease. ${ }^{4}$

Nahar et al. found that mean birth weight of infant increased by $20.2 \mathrm{~g}$ per kilogram of weight gain during pregnancy. ${ }^{5}$

Birth weight was correlated both with maternal weight in early pregnancy and with weight gain during pregnancy, but only $10 \%$ of the variation in birth weight was explained by these maternal factors. Mean maternal weight $24 \mathrm{~h}$ postpartum was equal to the weight at 14 weeks of pregnancy, implying, on the average, no net weight gain. Women with a positive net weight gain had heavier babies than women with a negative net weight gain. Maternal anthropometric characteristics are important underlying determinants of intrauterine growth and birth weight, but they explain only a minor part of the variation and are of little value for screening purposes in individual women. ${ }^{6}$

Maternal weight gain is one of the most important independent predictors of infant birth weight. Birth weight (BW) is an important determinant of infant's well being. Several factors such as mothers' genetic characteristics, socio-cultural, demographic, behavioural factors, prepregnancy body mass index (BMI), gestational weight gain (GWG) etc contribute to birth weight. BW is important as low birth weight is known to increase the risk of adult onset diseases like type -2 diabetes and ischemic heart disease. ${ }^{7}$

Nevertheless, maternal weight gain is associated with large infants i.e., macrosomia (>4000 g) or large for gestational age infants who have higher risk of birth injuries and other problems like shoulder dystocia, fractures of the clavicles or limbs, and perinatal asphyxia. The total amount of weight gained in normalterm pregnancies varies considerably among women and the variance appears to be due to many maternal characteristics and pregnancy outcomes. ${ }^{8}$

Weight gain during pregnancy has always been a matter of great concern for most women and obstetricians. This concern exists because gestational weight gain is related to many complications, both maternal and fetal. Macrosomia is a major fetal complication, consisting of cases of infants born weighing more than $4,000 \mathrm{~g}$, regardless of the gestational age. ${ }^{9}$ This higher weight is associated with complications for both the mother and the child. The most common complications in macrosomic fetuses include: increased risk of intrauterine death, hypertrophic cardiomyopathy, need for intensive care, shoulder dystocia, humeral and clavicle fractures, meconium aspiration, hypoglycemia, neonatal hyperbilirubinemia, paralysis of the facial and brachial plexus and obesity in childhood and adulthood. ${ }^{10,11}$ For mothers, the most common complications include: increased risk of cesarean section, cephalopelvic disproportion, prolonged labor, soft-tissue lacerations and postpartum hemorrhage. ${ }^{1}$

The present study was designed to determine the relationship between maternal weight gain and birth weight of new born at term.

\section{Materials And Methods:}

A cross sectional study was undertaken in department of Obstetrics and Gynaecology, Shaheed Suhrawardy Medical College and Hospital and Anwer Khan Modern Medical College Hospital during the period of January 2013 to July 2013.

Fifty pregnant women were included in study. Healthy pregnant women at term who were in regular antenatal checkup (37 completed weeks of gestational age) were included in this study. Pregnant women suffering from hypertension, pre-eclampsia, eclampsia, diabetes mellitus, thyroid dysfunction, nephritis were excluded from study. Data were collected in pre-designed data collection sheet. A structured questionnaire was developed and pre-teste before administration by the author. Data was collected from the pregnant mother admitted in the in-patient department for a period of 6 months. The data were collected by face to face interview for 
relevant information and measured the weight and height of the women before delivery and weight of the neonate were measured following delivery. Mothers weight was measured by a valid \& reliable weighing machine. Mother's height was measured with a height measuring scale. A valid and reliable neonatal weighing machine determined the neonatal weight. Written informed consent was taken from each patient. Prior to consent they were explained the aim and purpose of the research. Confidentiality and anonymity was maintained..

\section{Results:}

Table-I

Age distribution of the patients $(n=50)$

\begin{tabular}{lccc}
\hline Age in years & Frequency & Percent & Mean \pm SD \\
\hline$\leq 20$ & 14 & 28.0 & $25.00 \pm 5.43$ \\
$21-25$ & 18 & 36.0 & \\
$26-30$ & 12 & 24.0 & \\
$31-35$ & 4 & 8.0 & \\
$36-40$ & 2 & 4.0 & \\
\hline Total & 50 & 100.0 & \\
\hline
\end{tabular}

Table 1 shows maximum patients ( $36 \%$ ) belonged to age group $21-25$ years $28 \%$ were $\leq 20$ years, $24 \%$ were between $26-30$ years, $8 \%$ were between $31-35$ years and only $4 \%$ were between $36-40$ years. The mean age was $25 \pm 5.43$ years.

Table-II

Weight of the patients $(n=50)$

\begin{tabular}{lcc}
\hline Weight $(\mathrm{Kg})$ & Frequency & Percent \\
\hline$\leq 45 \mathrm{Kg}$ & 4 & 8.0 \\
$46-55 \mathrm{Kg}$ & 8 & 16.0 \\
$56-65 \mathrm{Kg}$ & 20 & 40.0 \\
$>65 \mathrm{Kg}$ & 18 & 36.0 \\
\hline Total & 50 & 100.0 \\
\hline
\end{tabular}

Table 2 shows $8 \%$ had birth weight $\geq 45 \mathrm{Kg}, 16 \%$ had birth weight $46-55 \mathrm{Kg}, 40 \%$ had birth weight 56-65 $\mathrm{Kg}$ and $36 \%$ had birth weight $>65 \mathrm{Kg}$.

Table-III

Weight gain during pregnancy $(n=50)$

\begin{tabular}{lccc}
\hline $\begin{array}{l}\text { Weight } \\
\text { gain }(\mathrm{Kg})\end{array}$ & Frequency & Percent & Mean \pm SD \\
\hline$\leq 5$ & 2 & 4.0 & \\
$6-10$ & 34 & 68.0 & $10.72 \pm 3.72$ \\
$>10$ & 14 & 28.0 & \\
\hline Total & 50 & 100.0 & \\
\hline
\end{tabular}

In $4 \%$ of women, weight gain during pregnancy was $\leq 5 \mathrm{~kg}$ in $68 \%$ weight gain was $6-10 \mathrm{~kg}$ and in $28 \%$ weight gain was $>10 \mathrm{~kg}$. The mean weight gain was $10.72 \pm 3.72 \mathrm{Kg}$. .

Table-IV

Birth weight of new born $(n=50)$

\begin{tabular}{lccc}
\hline Birth weight & Frequency & Percent & Mean \pm SD \\
\hline$\leq 2.5 \mathrm{~kg}$ & 12 & 24.0 & $2.77 \pm 0.33$ \\
$>2.5 \mathrm{~kg}$ & 38 & 76.0 & \\
\hline
\end{tabular}

Table 4 shows that $24 \%$ of the new born has birth weight $\leq 2.5 \mathrm{~kg}$ and $76 \%$ had birth weight $>2.5 \mathrm{Kg}$. The mean birth weight was $2.77 \pm 0.33$

Table-V

Relationship between maternal weight gain and birth weight of new born $(n=50)$

\begin{tabular}{lcccc}
\hline Maternal weight & Number & \multicolumn{2}{c}{ Birth weight } & P value \\
\cline { 3 - 4 } gain $(\mathrm{Kg})$ & & Mean & SD & \\
\hline$\leq 5 \mathrm{Kg}$ & 2 & 2.40 & 0.00 & 0.007 \\
$6-10 \mathrm{Kg}$ & 34 & 2.73 & 0.33 & \\
$>10 \mathrm{Kg}$ & 14 & 3.06 & 0.20 & \\
\hline
\end{tabular}

Table 5 shows birth weight was $2.40 \mathrm{~kg}$ in maternal weight gain $\leq 5 \mathrm{~kg}$, birth weight was $2.73 \mathrm{~kg}$ in maternal weight gain $6-10 \mathrm{~kg}$ and birth weight $3.06 \mathrm{~kg}$ in maternal weight gain $>10 \mathrm{~kg}$. So it is indicated that with an increase in weight gain during pregnancy there was a corresponding increase in mean birth weight and this increase was statistically significant $(P<0.05)$.

\section{Discussion:}

Maternal weight gain during pregnancy influenced by several trends in perinatal health that are of great public health concern. Women are increasingly gaining weight during pregnancy complications associated with excess gestational weight gain such as large-for-gestational-age babies. This is also important as the prevalence of cesarean delivery has also increased. Maternal weight gain during the $2^{\text {nd }}$ and $3^{\text {rd }}$ trimesters is an important determinant of fetal growth. Low maternal weight gain is associated with an increased risk of small for gestational age (SGA) infants, especially in underweight and normal-weight women. ${ }^{1}$

Birth weight is perhaps the most important and reliable indicator for neonatal and infant survival, its physical 
growth and mental development. As a universal indicator, it can be used to describe the health, nutrition and socio-economic status of population in both developed and developing countries. Currently, the incidence of low birth weight in India is 33 percent and as per National Health Policy efforts are being made to bring down the incidence to 10 percent by the year $2000 \mathrm{AD} .^{12}$

This study found maximum (36\%) were age group $21-25$ years followed by $28 \%$ were $\leq 20$ years, $24 \%$ were $26-30$ years, $8 \%$ were $31-35$ years and only $4 \%$ were $36-40$ years. The average age distribution of the present study was consistant with Rao et al. $1^{3}$ they found 25.2 years. Majority of the study subjects were housewives (88\%), literate (60\%), and belonged to middle income group (60\%). ${ }^{13}$

This study found majority were house wife (88\%). Regarding educational status, $4 \%$ were illiterate, $36 \%$ were can sign only, $12 \%$ were primary education, $20 \%$ were secondary education, $20 \%$ were higher secondary and $8 \%$ were master degree. In monthly income, $4 \%$ were monthly upper income group (>10000/month), $60 \%$ were middle income group (>5000-10000/month) and 36\% were lower income group (<5000/month); $8 \%$ had weight $\leq 45 \mathrm{Kg}, 16 \%$ had birth weight $46-55 \mathrm{Kg}, 40 \%$ had birth weight 56 $65 \mathrm{Kg}$ and $36 \%$ had birth weight $>65 \mathrm{Kg}$.

Among these 50 pregnant women, 2 cases (4\%) had $\mathrm{BMI}<18.5,15$ cases $(30 \%)$ had a BMI 18.5-24.9, 19 cases $(38 \%)$ had a BMI 25-29.9 and 14 cases $(28 \%)$ had a $\mathrm{BMI} \geq 30$. These women were categorized in BMl under weight, normal, overweight and obese. Study by Yazdani et al. ${ }^{14}$ showed among these 1000 pregnant women; 128 cases $(12.8 \%)$ had $\mathrm{BMI}<19.9,412$ cases (41.2\%) had a BMI 20-24.9, 356 cases $(35.6 \%)$ had a BMI 25-29.9, 98 cases (9.8\%) had a BMI $30-34.9$ and 6 cases $(0.6 \%)$ had a $\mathrm{BMI} \geq 35$.

This study shows $24 \%$ of the new born has birth weight $\leq 2.5 \mathrm{~kg}$ and $76 \%$ had birth weight $>2.5 \mathrm{Kg}$. The mean birth weight was $2.77 \pm 0.33$. $\mathrm{kg}$. The observed mean birth weight in the present study is comparable to studies conducted by Prasad et al. ${ }^{12}$ who observed a mean birth weight of $2823.6 \mathrm{gm}$ (SD=417.8 gm). This study shows among $4 \%$ of women, weight gain during pregnancy was $\leq 5 \mathrm{~kg}$ in $68 \%$ weight gain was $6-10 \mathrm{~kg}$ and $28 \%$ weight gain was $>10 \mathrm{~kg}$. The mean weight gain was $10.72 \pm 3.72$ $\mathrm{Kg}$. This findings are consistent with Rao et al. study ${ }^{13}$. The mean weight gain during pregnancy obtained in this study was also comparable to other studies carried out in India. However, the study conducted by Barbara ${ }^{15}$ found mean weight gains during pregnancy of $15.4 \mathrm{~kg}(\mathrm{SD}=5.2 \mathrm{~kg}$ ) which were higher than the findings of the present study.

In this study, we observed that there was a significant cor-relation between maternal weight gain and fetal birth weight. It is indicated that with an increase in maternal weight gain during pregnancy there was a corresponding increase in mean birth weight and this increase was statistically significant $(P<0.05)$. This findings consisted with Moreira et al. ${ }^{16}$ and they found significant correlation between maternal weight gain during pregnancy and birth weight of the new born. Another study Hymphreys ${ }^{17}$ reported maternal weight gain during gestation is positively correlated with birth weight. A population-based study conducted in the United States has shown that maternal weight gain during pregnancy correlates with birth weight. ${ }^{18}$ Rao et al. ${ }^{13}$ evaluated the relationship between various factors such as multiparity, pregestational overweight or obesity, advanced maternal age, prolonged gestational age and excessive gestational weight gain with the manifestation of fetal macrosomia. In that study, only excessive gestational weight gain was significantly associ-ated with macrosomia. Many studies conducted in India ${ }^{19,20}$ and in different parts of the world ${ }^{21,22}$ have proved the positive relationship between weight gain during pregnancy and birth weight. This study found significant association of BMI during pregnancy and birth weight of the new born. It found BMI below normal associated with low birth weight and $\mathrm{BMI}>30$ higher birth weight. The later result is similar to other studies from Ushakiran ${ }^{23}$ and Bhattacharya. It was also reported that BMI below normal is associated with a low birth rate, while a $\mathrm{BMI}>30$ increases the chance on a higher birth weight (2500-4000 or higher). This only suggests that weight gain during pregnancy is perhaps the most important variable irrespective of maternal height and period of gestation. It is a well established fact that period of gestation has an independent effect on birth weight.

\section{Conclusion:}

Weight gain during pregnancy, and maternal weight have emerged as maternal factors influencing the birth weight of the baby. In the present study, it was found that there was a direct relationship between maternal weight gain and fetal birth weight. Although challenging but public health efforts should continue working so that the nutritional status of women of 
reproductive age is optimal before they conceive as an apparent way to improve birth outcomes.

\section{References:}

1. Viswanathan $M$, Siega-Riz $A M$, Moos MK, Deierlein A, Mumford S, Knaack J, Thieda $P$, Lux LJ, Lohr KN. Outcomes of maternal weight gain. Evid Rep Technol Assess 2008;(168):1-223.

2. Rode L, Hegaard HK, Kjærgaard H, Møller LF, Tabor A, Ottesen B. Association Between Maternal Weight Gain and Birth Weight. Obstetrics \& Gynecology 2007;109(6):13091315.

3. Ludwig DS, Currie J. The association between pregnancy weight gain and birthweight: a withinfamily comparison. The Lancet 2010; 376(9745): 984 - 990,

4. Karim MR, Flora MS, Akhter S. Targeted food supplementation through National Nutrition Program and pregnancy weight gain status in selected upazilas. Bangladesh Med Res Counc Bull 2011; 37:71-75.

5. Nahar S, Mascie-Taylor CGN, Begum HA. Maternal anthropometry as a predictor of birth weight. Public Health Nutr 2006;10:965-70.

6. Möller B, Gebre-Medhin M, Lindmark G. Maternal weight, weight gain and birthweight at term in the rural Tanzanian village of Ilula. $\mathrm{Br} \mathrm{J}$ Obstet Gynaecol. 2009Feb;96(2):158-66.

7. Padilha PDC, Accioly E, Chagas C, Portela E, Da Silva CL, Saunders C. Birth weight variation according to maternal characteristics and gestational weight gain in Brazilian women. Nutr Hosp 2009; 24: 207-12.

8. Shrestha I, Sunuwar L, Bhandary S, Sharma P. Correlation between gestational weight gain and birth weight of the infants. Nepal Med Coll J 2010;12(2):106-109

9. Costa BM, Paulinelli RR, Barbosa MA.Association between maternal and fetal weight gain: cohort study. Sao Paulo Med. J. 2012;130(4): 242-247.

10. Clausen T, Burski TK, Øyen N. Maternal anthropometric and metabolic factors in the first half of pregnancy and risk of neonatal macrosomia in term pregnancies. A prospective study. Eur J Endocrinol. 2005;153(6):887-94.

11. Stotland NE, Cheng YW, Hopkins LM, Caughey $A B$. Gestational weight gain and adverse neonatal outcome among term infants. Obstet Gynecol. 2006;108(3 Pt 1):635-43.

12. Prasad KN, Phaneendra Rao RS. Study of low birth weight infants in coastal areas of Udupi Taluk, Karnataka, South India. Bahrain Med Bull 1994;16:90-4.

13. Rao PRS, Prakash KP, Nair S. Influence of PrePregnancy Weight, Maternal Height and Weight Gain During Pregnancy on Birth Weight. Bahrain Medical bulletin 2001; 23(1):75-85.

14. Yazdani S, Yosofniyapasha $\mathrm{Y}$, Nasab BH, Mojaveri MH, Bouzari Z. Effect of maternal body mass index on pregnancy outcome and newborn weight. BMC Research Notes 2012;5:34.

15. Barbara Adams and Steve Selvin. Maternal weight gain pattern and birth weight. Obstet Gynecol 1995; 86: 163-9.

16. P Moreira1,2, C Padez3, I Moura o-Carvalhal and $\mathrm{V}$ Rosado. Maternal weigh gain during pregnancy and overweight in Portuguese children. International Journal of Obesity (2007) $31,608-614$

17. Humphreys RC. An analysis of the maternal and foetal weight factors in normal pregnancy. $J$ Obstet Gynecol Br Emp 2004; 61:764-771.

18. Ludwig DS, Currie J. The association between pregnancy weight gain and birthweight: a withinfamily comparison. Lancet 2010; 376: 984-90.

19. Vijayalaxmi SV, Bharthi PA. Study of correlation between the maternal weight gain during pregnancy, height and serial serum protein estimation with fetal outcome. J Obstet Gynecol India 2001;31:418-23.

20. Pansari K, Bhuptani T, Yajnik ND. Pattern of weight gain in normal pregnancy and its usefulness for monitoring antenatal patients. J Obstet Gynecol India 2006;36:485-90.

21. Niswander KR, Singer J, Westphal M. Weight gain during pregnancy and pre-pregnancy weight. Obstet Gynecol 2009;33:482.

22. Verma TR. Maternal weight and weight gain in pregnancy and obstetric outcome. Int J Gynecol Obstet 2004;22:161.

23. UshaKiran TS, Hemmadi S, Bethel J, Evans J: Outcome of pregnancy in a women with an increased body mass index. An International Journal of Obstetrics and Gynecology 2005, 112(6):768-772. 